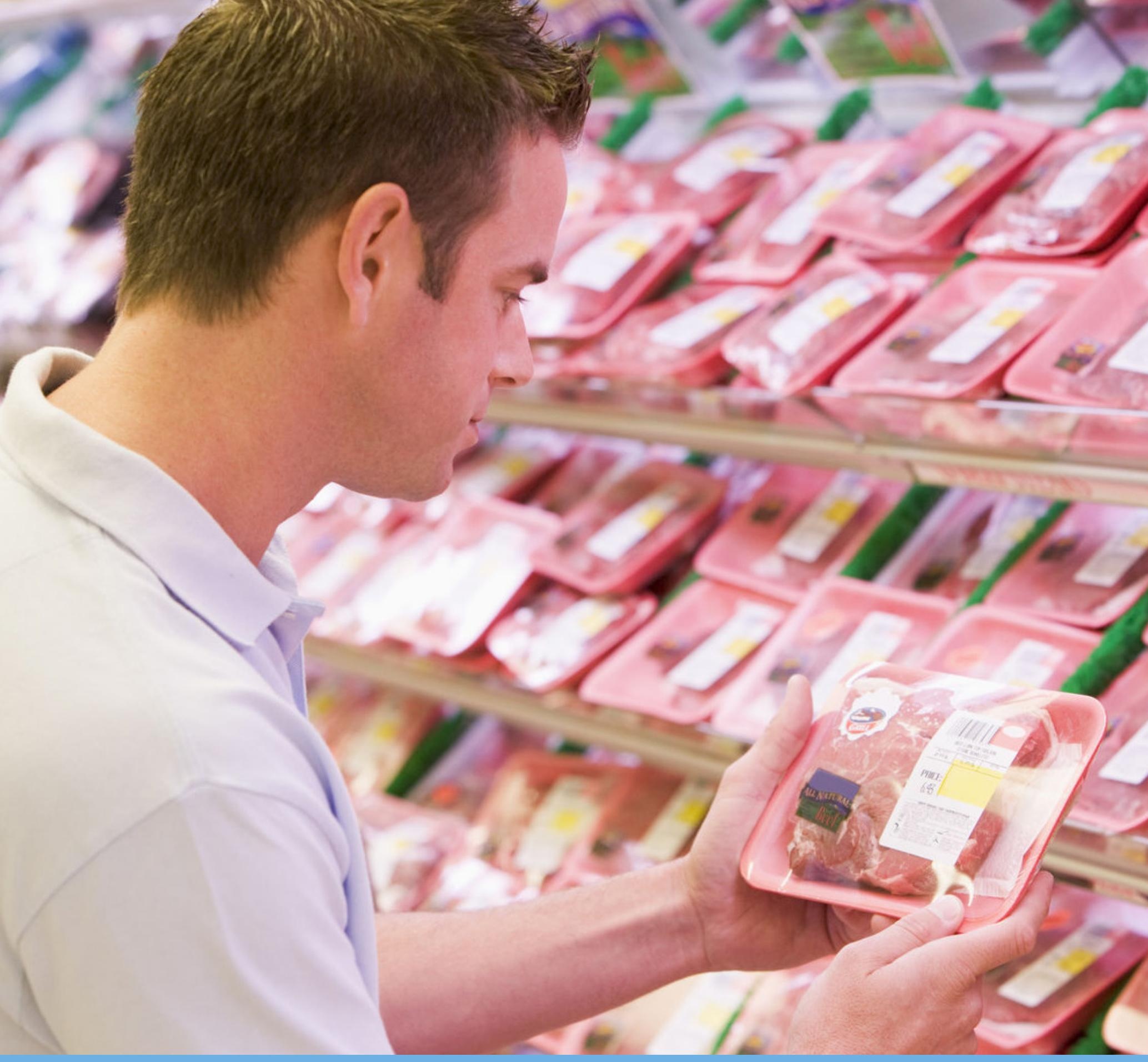

\title{
Vleesconsumptie per hoofd van de bevolking in Nederland, 2005-2018
}

Hans Dagevos, David Verhoog, Peter van Horne en Robert Hoste

WAGENINGEN

UNIVERSITY \& RESEARCH 



\section{Vleesconsumptie per hoofd van de bevolking in Nederland, 2005-2018}

Hans Dagevos, David Verhoog, Peter van Horne en Robert Hoste

Dit onderzoek is uitgevoerd door Wageningen Economic Research in opdracht van en gefinancierd door Wakker Dier. 
Hans Dagevos, David Verhoog, Peter van Horne en Robert Hoste, 2019. Vleesconsumptie per hoofd van de bevolking in Nederland, 2005-2018. Wageningen, Wageningen Economic Research, Nota 2019-108. 12 blz.; 1 fig.; 1 tab.; 9 ref.

Deze nota geeft een overzicht van de vleesconsumptie per hoofd van de bevolking in Nederland in de jaren 2005-2018. Het totale verbruik van vlees en vleeswaren per hoofd van de bevolking in Nederland ligt in 2018 iets boven de $77 \mathrm{~kg}$ (op basis van karkasgewicht). Dit is ruim een halve kilo meer dan in 2017.

Dit rapport is gratis te downloaden op https://doi.org/10.18174/499852 of op www. wur. nl/economicresearch (onder Wageningen Economic Research publicaties).

(C) 2019 Wageningen Economic Research

Postbus 29703, 2502 LS Den Haag, T 07033583 30, E communications.ssg@wur.nl, www.wur.nl/economic-research. Wageningen Economic Research is onderdeel van Wageningen University \& Research.

\section{(cc) BY-NC}

Wageningen Economic Research hanteert voor haar rapporten een Creative Commons Naamsvermelding 3.0 Nederland licentie.

(C) Wageningen Economic Research, onderdeel van Stichting Wageningen Research, 2019 De gebruiker mag het werk kopiëren, verspreiden en doorgeven en afgeleide werken maken. Materiaal van derden waarvan in het werk gebruik is gemaakt en waarop intellectuele eigendomsrechten berusten, mogen niet zonder voorafgaande toestemming van derden gebruikt worden. De gebruiker dient bij het werk de door de maker of de licentiegever aangegeven naam te vermelden, maar niet zodanig dat de indruk gewekt wordt dat zij daarmee instemmen met het werk van de gebruiker of het gebruik van het werk. De gebruiker mag het werk niet voor commerciële doeleinden gebruiken.

Wageningen Economic Research aanvaardt geen aansprakelijkheid voor eventuele schade voortvloeiend uit het gebruik van de resultaten van dit onderzoek of de toepassing van de adviezen.

Wageningen Economic Research is ISO 9001:2008 gecertificeerd.

Wageningen Economic Research Nota 2019-108 | Projectcode 2282100340

Foto omslag: Shutterstock 


\section{Inhoud}





\section{$1 \quad$ Inleiding}

Wakker Dier is geïnteresseerd in de omvang van de vleesconsumptie per hoofd van de bevolking in Nederland. Tot en met 2012 leverde de Productschappen voor Vee, Vlees en Eieren (PVE) deze informatie. Door de opheffing van de PVE kwam er een einde aan deze informatievoorziening. Wakker Dier heeft daarom Wageningen Economic Research benaderd om de vleesconsumptie per hoofd van de bevolking in Nederland te berekenen. Wageningen Economic Research heeft dit in 2015 voor het eerst gedaan (Verhoog et al., 2015). Ook heeft Wakker Dier gevraagd de huidige vleesconsumptie per hoofd van de bevolking in Nederland te vergelijken met eerdere jaren, zodat trends in de vleesconsumptie zichtbaar worden.

Deze nota geeft in hoofdstuk 3 een overzicht van de vleesconsumptie per hoofd van de bevolking in Nederland in de jaren 2005-2018 en maakt daarbij onderscheid naar de volgende vleessoorten: rundvlees, varkensvlees, schapen- en geitenvlees, paardenvlees, pluimveevlees en totaal vlees.

Het afsluitende hoofdstuk 4 geeft duiding en achtergrond aan de jongste cijfers. 


\section{Berekeningswijze}

Net als de PVE heeft Wageningen Economic Research de vleesconsumptie per hoofd van de bevolking uitgerekend op basis van de systematiek van de voorzieningsbalansen. Dat komt erop neer dat het verbruik in een bepaald jaar wordt afgeleid van het aantal slachtingen van dieren, de invoer en uitvoer van vlees zoals die in de CBS-statistieken te vinden zijn en de voorraadmutaties. Bij deze mutaties gaat het om vlees dat wordt opgeslagen in bijvoorbeeld een koelhuis om in het jaar daarop te worden geconsumeerd (voorraad wordt groter en verbruik dit jaar kleiner) of om vlees dat juist uit het koelhuis wordt gehaald om nu te worden geconsumeerd (voorraad wordt kleiner en verbruik groter). In de CBS-handelsstatistieken valt vlees uiteen in een groot aantal diersoorten en onderdelen van dieren, zoals schouders, achterdelen en ribstukken. Verder worden allerlei bewerkte vormen van vlees geregistreerd, zoals vers vlees, bevroren vlees, gedroogd vlees, gezouten vlees, hammen en vleeswaren. In totaal zijn meer dan 500 producten meegenomen, tot op een vrij gedetailleerd niveau. Producten waar vlees in zit verwerkt, zoals lasagne en kippensoep, zijn in deze berekeningen buiten beschouwing gelaten. Dat komt omdat het moeilijk is om op nationaal niveau te bepalen hoeveel vlees er in deze producten - die van verschillende fabrikanten afkomstig zijn - zit.

Voor voorraadmutaties van vlees bestaat geen bron die we kunnen gebruiken. Dat komt bij de berekeningen van voorzieningsbalansen voor andere producten dan vlees ook regelmatig voor; in zulke gevallen is het gebruikelijk dat de opstellers van de balans zelf een aanname voor de voorraadmutatie maken. In het geval van de voorzieningsbalans voor vlees is dat als volgt gedaan: we veronderstellen dat het verbruik bestaat uit directe consumptie en het aanleggen van een voorraad. Voor het berekende verbruik is op basis van expertise een inschatting gemaakt van de voorraadmutaties, waarbij ook rekening is gehouden met een inschatting voor buitenshuisconsumptie en met de jaarlijkse mutatie van de aankopen door consumenten per vleessoort op basis van GfK-data. Met deze data kan een betere inschatting gemaakt worden van de verhouding tussen de directe consumptie en het deel bestemd voor de voorraad in het berekende verbruik. GfK-data zijn gebaseerd op de aankopen van levensmiddelen bij de detailhandel in Nederland door een panel van 6.000 personen.

Verder zijn de berekeningen alleen gericht op menselijke consumptie van vlees en vleesproducten. De consumptie van slachtbijproducten door (huis)dieren (zoals honden, katten, nertsen) is buiten beschouwing gelaten.

De berekeningen van de vleesconsumptie gaan over vlees en vleesproducten, zonder de eetbare slachtbijproducten zoals lever en vetten. Deze werkwijze sluit aan bij de internationaal gangbare aanpak. 


\section{Vleesconsumptie per hoofd van de bevolking}

Het totale verbruik van vlees en vleeswaren (op basis van karkasgewicht) per hoofd van de bevolking in Nederland beloopt in 2018 iets meer dan $77 \mathrm{~kg}$ (Tabel 3.1). Deze hoeveelheid ligt ruim een halve kilo boven het verbruik in 2017. Hiermee is er voor het eerst na vele jaren weer enige stijging in de vleesverbruikcijfers en wordt na enige jaren weer de grens van $77 \mathrm{~kg}$ gepasseerd. Voor het merendeel komt dit door een toename in het verbruik van pluimveevlees en voor de rest door een marginale toename van varkens- en rundvlees. De cijfers voor de overige vleessoorten die zijn onderscheiden blijven gelijk aan eerdere jaren.

De verhoudingen tussen de verschillende soorten vlees veranderen nauwelijks in 2018 ten opzichte van voorgaande jaren. Varkensvlees is en blijft de grootste categorie. Bijna de helft van het verbruik in 2018 - ruim $36 \mathrm{~kg}$ - bestaat uit varkensvlees (Figuur 3.1). Pluimveevlees en rundvlees samen zijn goed voor vrijwel de andere helft van de vleesconsumptie in Nederland (38 kg). De in tabel en figuur 3.1 gepresenteerde cijfers gaan over het verbruik op basis van karkasgewicht, dus vlees inclusief been, vet en zwoerd. Als vuistregel geldt dat daarvan ongeveer de helft feitelijk geconsumeerd wordt als vlees en vleeswaren. Dit betekent dat, op basis van een ruime kilo karkasgewicht, we in Nederland in 2018 gemiddeld per hoofd meer dan een halve kilo kalfsvlees hebben gegeten en dat hetzelfde geldt voor de grootte van de geconsumeerde hoeveelheid schapen- en geitenvlees. Het aandeel van paardenvlees blijft onveranderlijk minimaal in Nederland.

De 2018-cijfers betekenen dat er voor het eerst in 10 jaar weer een oplopende trend is. In de jaren 2008-2009 noteerden we voor het laatst een stijging. Daarna daalde het verbruik in Nederland van zo'n 79 kg in 2010 naar onder de 77 kg in 2015 per hoofd van de bevolking. De jaren 2016 en 2017 kenmerkten zich door een stabilisatie in het vleesverbruik - de hoeveelheid van 76,7 kg betekende bovendien een stabilisatie op het niveau van 2005. De periode (2010-2015) van een licht dalende trend in het vleesverbruik kwam daarmee ten einde. Het iets stijgende vleesverbruik in Nederland dat de 2018-cijfers laten zien, maakt dat er verder afstand wordt genomen van die periode.

In het navolgende hoofdstuk wordt nader duiding gegeven aan het voor 2018 bereikte resultaat.

Tabel 3.1 Vleesverbruik a) per hoofd van de bevolking in Nederland, 2005-2018 (kg)

\begin{tabular}{lrrrrrrrrrrrrrr} 
& 2005 & 2006 & 2007 & 2008 & 2009 & 2010 & 2011 & 2012 & 2013 & 2014 & 2015 & 2016 & 2017 & 2018 \\
Varkensvlees & 37,2 & 37,4 & 37,6 & 37,8 & 37,7 & 37,7 & 37,7 & 37,3 & 37,1 & 36,7 & 36,6 & 36,5 & 36,5 & 36,6 \\
\hline Pluimveevlees & 20,7 & 20,8 & 21,5 & 21,6 & 22,5 & 22,5 & 22,1 & 22,0 & 22,3 & 22,5 & 22,1 & 22,2 & 22,1 & 22,5 \\
\hline Rundvlees & 15,9 & 16,1 & 16,1 & 16,1 & 16,3 & 16,2 & 15,9 & 15,7 & 15,6 & 15,5 & 15,4 & 15,4 & 15,4 & 15,5 \\
\hline Kalfsvlees & 1,3 & 1,3 & 1,3 & 1,4 & 1,4 & 1,3 & 1,3 & 1,3 & 1,3 & 1,3 & 1,3 & 1,3 & 1,3 & 1,3 \\
\hline Schapen- en & 1,0 & 1,0 & 1,0 & 1,1 & 1,1 & 1,1 & 1,1 & 1,1 & 1,2 & 1,2 & 1,2 & 1,2 & 1,2 & 1,2 \\
geitenvlees & & & & & & & & & & & & & \\
\hline Paardenvlees & 0,6 & 0,5 & 0,2 & 0,1 & 0,1 & 0,1 & 0,1 & 0,1 & 0,1 & 0,1 & 0,1 & 0,1 & 0,1 & 0,1 \\
\hline Totaal vlees & 76,7 & 77,1 & 77,8 & 78,1 & 79,1 & 79,0 & 78,2 & 77,6 & 77,5 & 77,3 & 76,7 & 76,6 & 76,6 & 77,2 \\
\hline
\end{tabular}

a) Op basis van karkasgewicht (gewicht met been).

Bron: CBS, berekening Wageningen Economic Research. 


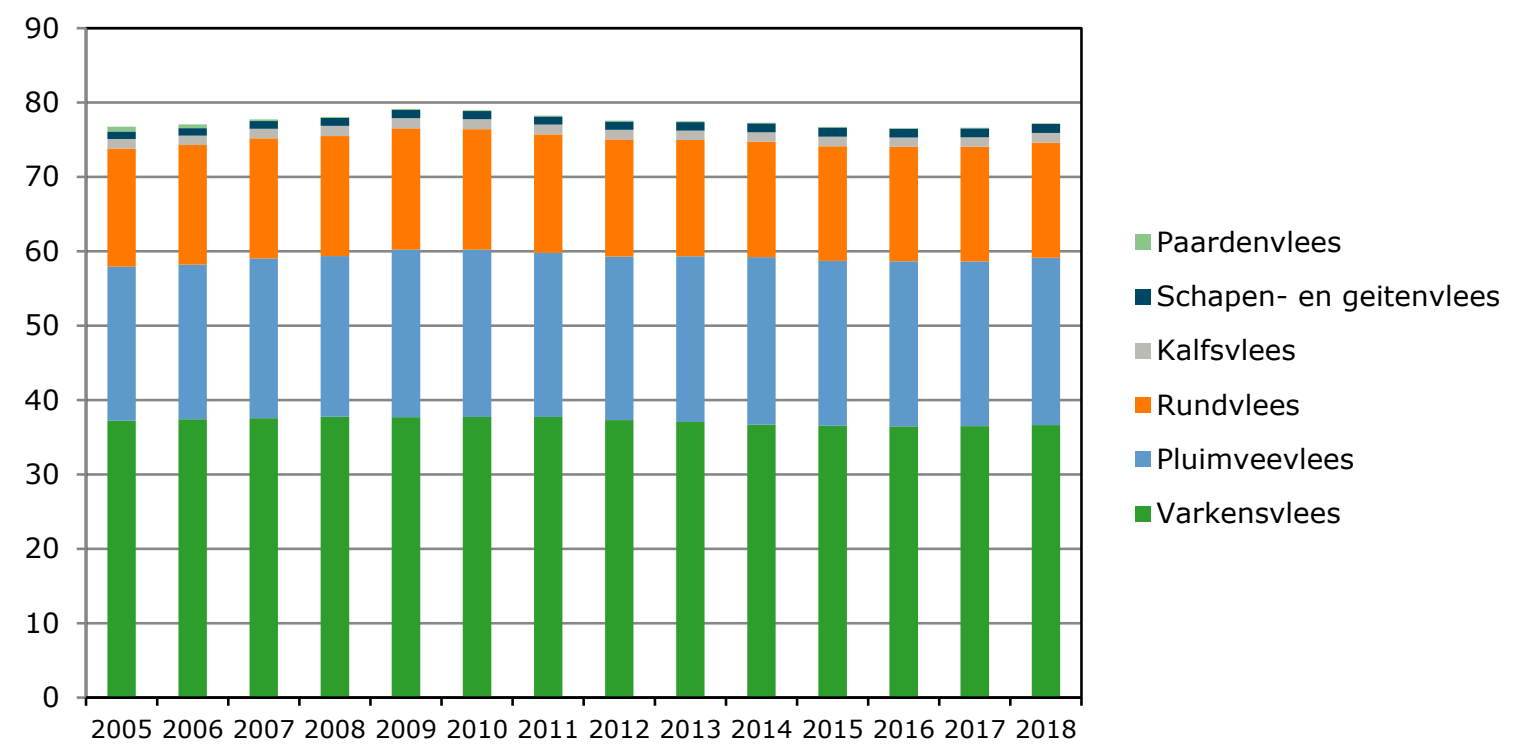

Figuur 3.1 Vleesverbruik a) per hoofd van de bevolking in Nederland, 2005-2018 (kg)

a) Op basis van karkasgewicht (gewicht met been).

Bron: CBS, berekening Wageningen Economic Research. 


\section{$4 \quad$ Vlees eten blijft gebruikelijk}

In het slothoofdstuk van Vlees vooral(snog) vanzelfsprekend (Dagevos et al., 2012) worden woorden van Jaap van Ginneken aangehaald: 'Vleesgebruik is kennelijk zó diep in het voedingspatroon ingesleten, dat het voor de meesten moeilijk is om los te laten' (Van Ginneken, 2001: 78). We voegden aan dit citaat uit het begin van deze eeuw in 2012 toe: 'Dit is onverkort geldig.' (Dagevos et al., 2012: 86.) Intussen zijn we opnieuw jaren verder en beide citaten zijn nog steeds actueel. Immers, de 2018-cijfers geven aan dat voor veel Nederlanders het gebruikelijke voedingspatroon vleesrijk is. Vlees blijft ook vandaag de dag vooral vanzelfsprekend.

$\mathrm{Na}$ deze constatering is de stijging van de vleesconsumptie in 2018 met een ruime halve kilo wel opvallend. Om te beginnen vanwege het verschil met de voorgaande jaren (2010-2015) van enige terugloop en de laatste paar jaar (2016-2017) van stabilisatie.

De 2018-cijfers zijn ook opvallend nadat het marktbureau IRI in augustus 2019 melding maakte van een daling in de hoeveelheid roodvleesproducten (rund-, varkensvlees en wild) dat voorbij de kassa's van een aantal supermarktketens is gegaan sinds 2017 tot medio 2019 (Veerman, 2019). Dit is een andere en minder omvattende wijze van dataverzameling dan de hier gehanteerde berekeningswijze. Maar het is prima verschillende bronnen over de marktvraag naar vlees te hebben. Ze helpen bij het verkennen van de vleesconsumptie en laten zien dat elke benaderingswijze beperkingen kent. Zo is aan de hand van onze cijfers alleen te speculeren of de 2018-ontwikkeling mogelijk te maken heeft met de prijzen van vlees, met verbeteringen in de inkomens van mensen, met een lang 'barbecueseizoen' vanwege het vele mooie weer in 2018 of wellicht ook met een stijging in de horecamaaltijden die aan een toenemend aantal toeristen zijn geserveerd. Nader onderzoek kan bijdragen aan onderbouwde reacties op suggesties als deze.

De cijfers zijn eveneens opvallend omdat van diverse kanten - gebaseerd op macro-analyses over de uitdagingen hoe de klimaatproblematiek en voedselzekerheidsvragen op te lossen rond een groeiende en meer welvarende bevolking - wordt gepleit voor een verschuiving van het aandeel dierlijke eiwit naar het aandeel plantaardige eiwitten (en in de westerse wereld bovendien een daling van het totaal). Deze boodschap vindt brede wetenschappelijke weerklank. Hiernaast krijgen flexitarisme (vleesminderen) en meer plantaardig eten de nodige aandacht van media, maatschappelijke organisaties, onderzoekers, adviesraden, koks en consumenten, worden de marktprognoses voor plantaardige vleesvervangers rooskleurig voorgesteld en zijn (grote) voedingsbedrijven en kapitaalkrachtige partijen tegenwoordig volop actief op deze markt. In dit licht is het niet vreemd te vermoeden dat de vraag naar vlees af zou nemen. Maar de cijfers over 2018 volgen dit verwachtingspatroon niet. Evenals de gelijkblijvende vleesconsumptie die de 2017-cijfers lieten zien, geeft het gevonden vleesverbruik voor 2018 aanleiding, net als vorig jaar (Dagevos et al., 2018: 8; zie ook Dagevos en Temme, 2018), ons af te vragen hoe het is te begrijpen dat we een hoeveelheid vlees blijven eten die aanmerkelijk groter is dan de Richtlijnen goede voeding aanbeveelt.

Vanuit het perspectief van een overheid die wil bevorderen dat we meer gaan eten volgens deze voedingsrichtlijnen (Schijf van Vijf), geven de jongste cijfers aan dat een zogenoemde eiwittransitie aan de vraagzijde van de markt geen automatisme is. In de recent verschenen studie Dagelijkse kost (PBL, 2019) wordt naar voren gebracht dat verduurzaming van het consumptiepatroon beïnvloed wordt door de voedselomgeving, voedselvaardigheden en culturele betekenissen van voedsel. De eerste betreft, kortweg en met het oog op vleesconsumptie, de wijze waarop en de mate waarin vleesproducten worden aangeboden en aangeprezen en welke aandacht en aanprijzing vleesarm of vleesloos eten krijgen. Voedselvaardigheden hebben bijvoorbeeld betrekking op het (meer) plantaardig kunnen koken of bekend zijn met het kiezen voor een vleesarme of plantaardige productvariant in de supermarkt. Hoe belangrijk beide ook zijn, we willen hieronder de nadruk leggen op de sociaal-culturele betekenis van voedsel. Dit ook omdat er regelmatig wordt aangegeven dat een andere eetcultuur geboden is wil vleesminderen normaliseren. In de heersende hedendaagse 
eetcultuur is vlees eten de norm. In het onderzoek hebben we het wel over de 4Ns (natural, normal, necessary, nice) die hieraan ondersteuning geven (Piazza et al., 2015). Oftewel, de eetculturele standaard is dat vlees eten normaal, noodzakelijk, logisch en lekker is. Dit betekent allerminst dat vleesminderen of vleesloos eten abnormaal zijn. Sterker, in Nederland is de emancipatie hiervan intussen ver genoeg gevorderd dat in veel sociale kringen een flexitarisch of vegetarisch eetpatroon geen issue is. Maar gelijktijdig betekent de vleesetende norm dat substantieel en structureel minder vlees consumeren niet zomaar het nieuwe normaal gaat worden. De nieuwste 2018-cijfers voeden deze veronderstelling.

Bij wat normaal is staan we vaak niet stil en we zien geen (noodzaak tot een) alternatief. De gangbare opvatting is zoiets als: zo is het nu eenmaal en het hoeft evenmin anders. Van de gevestigde norm zijn we overtuigd. Deze status quo kent sterke 'verdedigingsmechanismen', zoals het ontkennen, negeren, onderdrukken of herformuleren van ongemakkelijke informatie of van de aantrekkelijkheid van alternatieve gedragskeuzes die de (vaste) overtuiging ontkrachten. Behalve dat er sterke individuele gedragsmechanismen zijn die in dienst staan van het handhaven van het bekende gedrag en het weghouden van argumenten of keuzemogelijkheden die daarvan afwijken, zijn er ook 'bovenindividuele' aspecten aan te wijzen die helpen om te begrijpen waarom mensen onverminderd vlees eten. Deze concretiseren ook de cultuurverandering die in discussies over vlees eten wordt genoemd, maar die vaak abstract blijft.

In een onlangs gepubliceerde studie van Merin Oleschuk en collega's (2019) wordt verkend van welk sociaal-cultureel repertoire mensen gebruikmaken als ze ondervraagd worden over het consumeren van vlees. Het uitgangspunt van de studie van Oleschuk et al. is hier direct van toepassing omdat de onderzoekers zich eveneens de vraag stellen hoe het te rijmen is dat de vleesconsumptie in Europa en Noord-Amerika relatief hoog blijft terwijl er tegelijkertijd steeds meer aandacht is voor aspecten van klimaat en milieu, dierenwelzijn en gezondheid rondom de productie en consumptie van vlees.

Op basis van interviews in Canada vinden Oleschuk en collega's twee verklaringsrepertoires. De eerste betreft het identiteitsrepertoire, dat betrekking heeft op hoe mensen zichzelf zien en identificeren als persoon of onderdeel van een groep. Dit valt in twee hoofdcategorieën uiteen. Enerzijds verklaren mensen - veelal mannen in dit geval - vleesconsumptie vanuit de gevoelde noodzaak vlees te eten omdat dit mannelijk wordt gevonden en bovendien nodig om lijf en leden sterk en atletisch te houden. Ook als deze redenering vergezeld gaat van een glimlach of nuancerende opmerking blijft ze wel een rationalisering voor het eten van vlees. Anderzijds wordt het belang dat aan het eten van vlees wordt gehecht uitgelegd en gerechtvaardigd door een beroep te doen op de sociaal-culturele verbinding die vlees symboliseert en bevestigt. Eten en delen van vlees drukt connectie en traditie uit.

Het tweede is het zogenaamde vrijheidsrepertoire, dat in meer abstracte zin inhoud geeft aan rechten en plichten van mensen en dus betrekking heeft op welk meer algemeen mensbeeld men voor ogen heeft. Het vrijheidsrepertoire is eveneens in tweeën onder te verdelen. Aan de ene kant is er het beeld van de mens als consument die zich niet hoeft te bekommeren om problematische aspecten van de consumptieve keuzes die we maken. Vlees eten geldt als vanzelfsprekend waar verder weinig en kritisch over nagedacht wordt of er wordt geredeneerd dat je er als individuele consument toch niks aan kan veranderen. Aan de andere kant wordt de - zeker in neoliberale tijden - prominente positie van keuzevrijheid aangevoerd. Vlees eten wordt gekoppeld aan het beeld van de 'soevereine' consument die in alle vrij- en blijheid mag kiezen wat hem of haar pleziert en goeddunkt. Het gaat hier om de autonomie en het recht om te kiezen voor het eten van vlees. Ook dit repertoire levert belangrijke beweegredenen voor mensen om vlees te blijven consumeren.

De studie van Oleschuk c.s. helpt bij het concretiseren van culturele aspecten die samenhangen met vleesconsumptie. Cultuurverandering kan daarmee meer focus krijgen. De betekenis van vlees en de betekenis van de keuze voor vlees zijn voor mensen geen achterhaalde zaken, illustreert het Canadese onderzoek. Het zou niet verbazen wanneer ook onder Nederlanders soortgelijke beweegredenen zijn aan te treffen. In dat geval leveren ze een bijdrage aan het duiden van de hoog gebleven vleesverbruikcijfers. Vervolgonderzoek in deze richting kan bijdragen aan inzichten in de (aantrekkings)kracht van gebruikelijke eetpatronen in de context van gedragsverandering in de richting van de voedingsrichtlijnen. 


\section{Literatuur en websites}

Dagevos, H., J. Voordouw, L. van Hoeven, C. van der Weele en E. de Bakker (2012). Vlees vooral(snog) vanzelfsprekend: consumenten over vlees eten en vleesminderen. Den Haag: LEI Wageningen UR. http://edepot.wur.nl/212318

Dagevos, H., D. Verhoog, P. van Horne en R. Hoste (2018). Vleesconsumptie per hoofd van de bevolking in Nederland, 2005-2017. Wageningen: Wageningen Economic Research.

http://library.wur.nl/WebQuery/wurpubs/fulltext/464580

Dagevos, H. en L. Temme (2018). Vleesconsumptie in Nederland: gedrag gedraagt zich anders dan gedacht. Voeding $\mathrm{Nu}, 20,8-11$.

https://www.voedingnu.nl/algemeen/artikel/2019/01/vleesconsumptie-in-nederland-gedraggedraagt-zich-anders-dan-gedacht-10112113

Ginneken, J. van (2001). Schokgolf: omgaan met opinie-dynamiek. Amsterdam: Boom.

Oleschuk, M., J. Johnston en S. Baumann (2019). Maintaining meat: cultural repertoires and the meat paradox in a diverse sociocultural context. Sociological Forum. https://doi.org/10.1111/socf.12500

PBL (2019). Dagelijkse kost: hoe overheden, bedrijven en consumenten kunnen bijdragen aan een duurzaam voedselsysteem. Den Haag: Planbureau voor de Leefomgeving.

https://www.pbl.nl/sites/default/files/cms/publicaties/PBL-2019-dagelijkse-kost-bijdragen-aanduurzaam-voedselsysteem-2638.pdf

Piazza, J., M.B. Ruby, S. Loughnan, M. Luong, J. Kulik, H.N. Watkins en M. Seigerman (2015). Rationalizing meat consumption: the 4Ns. Appetite, 91, 114-128.

https://doi.org/10.1016/j.appet.2015.04.011

Veerman, D. (2019). CBS kan daling vleesconsumptie niet bevestigen en wil onderbouwing van de NOS. https://www.foodlog. nl/artikel/cbs-kan-daling-vleesconsumptie-niet-bevestigen-en-wilonderbouwing-van-de-n/

Verhoog, D., H. Wijsman en I. Terluin (2015). Vleesconsumptie per hoofd van de bevolking in Nederland, 2005-2014. Den Haag: LEI-Wageningen UR. http://edepot.wur.nl/359425 
Wageningen Economic Research Postbus 29703

2502 LS Den Haag

T 0703358330

Ecommunications.ssg@wur.nl

www.wur.nl/economic-research

Wageningen Economic Research NOTA

2019-108
De missie van Wageningen University \& Research is 'To explore the potential of nature to improve the quality of life'. Binnen Wageningen University \& Research bundelen Wageningen University en gespecialiseerde onderzoeksinstituten van Stichting Wageningen Research hun krachten om bij te dragen aan de oplossing van belangrijke vragen in het domein van gezonde voeding en leefomgeving. Met ongeveer 30 vestigingen, 5.000 medewerkers en 10.000 studenten behoort Wageningen University \& Research wereldwijd tot de aansprekende kennisinstellingen binnen haar domein. De integrale benadering van de vraagstukken en de samenwerking tussen verschillende disciplines vormen het hart van de unieke Wageningen aanpak. 



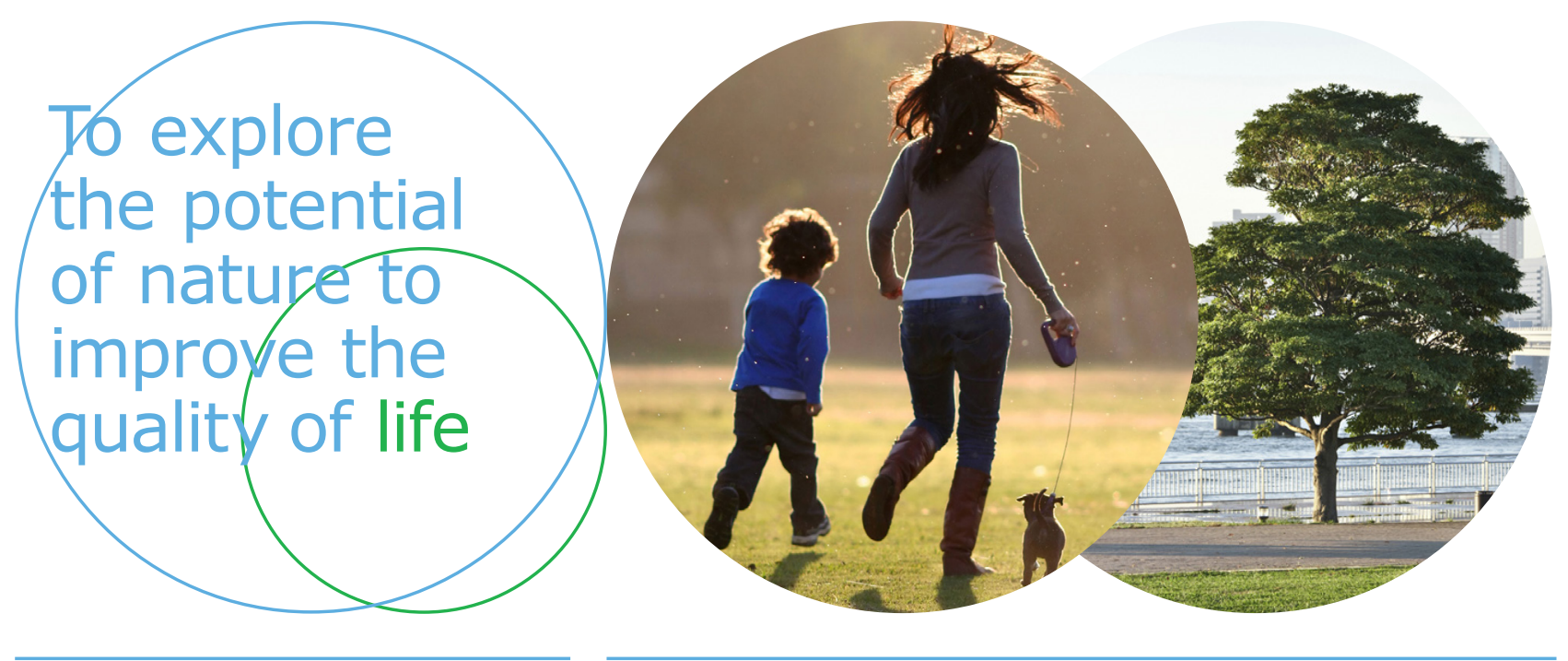

Wageningen Economic Research Postbus 29703

2502 LS Den Haag

E communications.ssg@wur.nl

$\mathrm{T}+31(0) 703358330$

www.wur.nl/economic-research

Nota 2019-108
De missie van Wageningen University \& Research is 'To explore the potential of nature to improve the quality of life'. Binnen Wageningen University \& Research bundelen Wageningen University en gespecialiseerde onderzoeksinstituten van Stichting Wageningen Research hun krachten om bij te dragen aan de oplossing van belangrijke vragen in het domein van gezonde voeding en leefomgeving. Met ongeveer 30 vestigingen, 5.000 medewerkers en 10.000 studenten behoort Wageningen University \& Research wereldwijd tot de aansprekende kennisinstellingen binnen haar domein. De integrale benadering van de vraagstukken en de samenwerking tussen verschillende disciplines vormen het hart van de unieke Wageningen aanpak. 